\title{
A produção do cuidado em saúde mental: avanços e desafios à implantação do modelo de atenção psicossocial territorial
}

I 1 Jeanine Maria Sobral Nunes, ${ }^{2}$ José Maria Ximenes Guimarães,

${ }^{3}$ José Jackson Coelho Sampaio I

Resumo: Objetiva-se compreender as razões de implantação do modelo de atenção psicossocial territorial, seus avanços e desafios na produção do cuidado, no atual movimento de Reforma Psiquiátrica ocorrido em Fortaleza, Ceará. A pesquisa é de natureza qualitativa, por via de estudo de caso, contextualizado historicamente, e de aproximação com o método dialético, tecnicamente, por meio de entrevista e grupo focal, com resultados submetidos à Análise do Discurso Coletivo. Os resultados e a discussão se expressam em categorias surgidas dos discursos dos trabalhadores, gestores e usuários, relacionadas aos modelos psiquiátrico clássico e de atenção psicossocial territorial. Do conjunto da investigação, afloraram as considerações finais, indicando que convivem tanto o modelo hospitalar quanto o modelo de atenção psicossocial territorial, não tendo havido superação do primeiro pelo segundo. Apesar da perspectiva de uma política de ação includente e integrada, o trânsito para a prática é descontínuo e fragmentário. Dessa forma, o modelo de atenção psicossocial territorial é expresso, atualmente, fora da realidade dos serviços, estranho/ alienado, sem muitas perspectivas de elaboração e execução em Fortaleza, Ceará.

> Palavras-chave: saúde mental; centros de atenção psicossocial; atenção à saúde.

\author{
1 Centro de Ciências da Saúde, \\ Universidade Estadual do \\ Ceará. Fortaleza-CE, Brasil \\ (jeaninenunes@hotmail.com). \\ ${ }^{2}$ Centro de Ciências da Saúde, \\ Universidade Estadual do \\ Ceará. Fortaleza-CE, Brasil \\ (jm_ximenes@hotmail.com). \\ ${ }^{3}$ Centro de Ciências da Saúde, \\ Universidade Estadual do \\ Ceará. Fortaleza-CE, Brasil \\ (sampaiojackson@gmail.com).
}

Recebido em: 25/01/2016 Aprovado em: 22/06/2016 
A Reforma Psiquiátrica no Brasil, no Ceará e em Fortaleza, configura-se como um movimento político-social, historicamente marcado por diversos avanços, porém com desafios relevantes na sua implementação. Legitimada por um arcabouço legal, cuja base é a Constituição de 1998, a criação e regulamentação do Sistema Único de Saúde (SUS), a reforma encontra sua fundamentação na legislação específica, expressa na Lei no 10.216/2001 (BRASIL, 2004), bem como nas diversas portarias editadas e atualizadas constantemente pelo Ministério da Saúde, o que dá sustentação normativa a esse processo. Sua efetivação no cotidiano dos trabalhadores e usuários, no entanto, é constituída atualmente por passos imbricados na tensão permanente entre a sobrevivência do modelo psiquiátrico clássico e a proposta do modelo de atenção psicossocial territorial.

Os traços que demarcam a configuração dos modos de operacionalização das práticas no campo da Saúde Mental moldam os modelos de atenção, tipificados por Sampaio (1988) como modelo asilar e modelo psiquiátrico clássico. Nessa obra, o autor sinaliza o desenvolvimento do terceiro modelo, denominado psicossocial territorial, que foi mais bem caracterizado em trabalhos posteriores (SAMPAIO, 2001; 2006; SAMPAIO; GUIMARÃES; ABREU, 2010; SAMPAIO et al., 2011).

O modelo asilar, centrado na exclusão de incuráveis e na tutela plena, consolidado durante o século XIX, denota sintonia com uma cultura autoritária, assentada na violência contra os que não se enquadram nos modelos sociais ideais. O modelo psiquiátrico clássico, hospitalocêntrico, tem como traço fundamental a centralidade na doença e no combate aos seus sintomas, sob a hegemonia biológica e com a visão organopositivista e nas relações biunívocas de causa-efeito (SAMPAIO, 1998; 2001). De algum modo, esses modelos se reproduzem atualmente, sua permanência se caracterizando pela convivência superposta ou híbrida de ambos na sociedade brasileira, cearense e fortalezense. Esta, por sua vez, enseja a reprodução da lógica de tratamento com ênfase no controle dos sintomas por meio da prescrição de medicamentos, e, por vezes, da internação psiquiátrica. Nesses termos, o doente se torna útil ao complexo médico-industrial, como consumidor de planos de saúde, serviços ambulatoriais/ hospitalares, exames laboratoriais e medicamentos. Por conseguinte, a doença é o objeto de intervenção e o sujeito é caracterizado como subcidadão, desprovido de protagonismo e autonomia, tendo seus direitos violentados. 
O modelo da atenção psicossocial territorial, constituído e implementado no contexto da Reforma Psiquiátrica, caracteriza-se pela ampliação do conceito de saúde, considerando as concepções da produção histórica do papel de doente e do cuidado integral e humanizado, superando a visão nosológica e individualizada, que condiciona o seu significado à ausência de doença ou à utopia de completo bem-estar biopsicossocial. Nesse modelo, o objeto de intervenção se desloca da doença para o sujeito em sofrimento psíquico, considerando sua constituição política, histórica e sociocultural, reconhecendo a complexidade do processosaúde doença e elegendo o território como espaço de produção do cuidado, o que requer articulação intersetorial (SAMPAIO; GUIMARÃES; ABREU, 2010; GUIMARÃES, 2012). De acordo com Sampaio (1998), saúde e doença mental estão intrinsecamente ligadas ao contexto socioeconômico e cultural, não se configurando, portanto, como fenômenos isolados que possam ser definidos em si mesmos. A doença mental ocorre quando há a fragilidade ou a perda das narrativas relacionais entre história psíquica do indivíduo e a história da sociedade.

$\mathrm{Na}$ transição do modelo psiquiátrico clássico para o psicossocial territorial, um dos maiores entraves percebidos é a sobrevivência de um padrão sociocultural que legitima a segregação das diferenças. Apesar dos avanços, principalmente em termos legislativos, mas também na ampliação dos serviços componentes da Rede de Atenção Psicossocial (RAPS), percebem-se a manutenção e/ou reprodução do modelo asilar/psiquiátrico clássico, o que, na tensão conflitual, favorece o adoecimento dos usuários e, também, dos trabalhadores de saúde mental.

Convém destacar que o processo de Reforma Psiquiátrica no Ceará tem início no interior do estado, quando se inaugura o primeiro Centro de Atenção Psicossocial (CAPS), em 1991, na cidade de Iguatu. Na capital, Fortaleza, havia hegemonia do modelo psiquiátrico clássico, cristalizado na existência de sete hospitais psiquiátricos, razão pela qual somente em 1998 foi implantado o primeiro CAPS, seguido de mais dois em 2001. Posteriormente, em 2005, ocorre a decisão técnico-política da gestão municipal de, efetivamente, ampliar a rede de serviços substitutivos, mediante a implantação de 11 novos CAPS, totalizando 14 equipamentos dessa natureza. Evidencia-se, portanto, que o CAPS assume caráter estratégico na reorientação do modelo de atenção à saúde mental, mediante a sua expressiva expansão. 
Ressalta-se que os CAPS, como serviços públicos de saúde, integrantes do SUS, devem atuar visando materializar os princípios que fundamentam esse sistema, garantindo universalidade, equidade, integralidade, descentralização, participação democrática dos diferentes atores (gestores, trabalhadores, usuários e seus familiares) e resolubilidade do cuidado. De acordo com seu caráter estratégico, assumem posição central na articulação da rede de cuidados, agregando os três níveis de atenção, o direcionamento local de políticas e programas de saúde mental e a promoção de reflexões contínuas acerca do modelo de gestão do trabalho, do modelo de atenção e da clínica operada no seu cotidiano (CAMPOS et al., 2009; SILVA; LANCMAN; ALONSO, 2009; SAMPAIO; GUIMARÃES; ABREU, 2010).

Reconhece-se a importância da expansão do quantitativo CAPS, no entanto, sabe-se que velhos modelos podem se reproduzir com novas roupagens. $\mathrm{Ou}$, ainda, a implantação de um modelo não suprime de imediato o anterior. Ao contrário, ambos podem conviver simultaneamente, apesar de suas contradiçōes e antagonismos. Há, portanto, o risco de reprodução dos seus fundamentos filosóficos, ético-políticos, teóricos e práticos nos serviços constitutivos do novo modelo (QUINDERÉ et al., 2010).

Nesse contexto, mostra-se relevante compreender como essa tensão se manifesta após mais de dez anos de implantação dos CAPS em Fortaleza. Partese do pressuposto de que poderia ser pela implantação parcial e truncada do novo modelo, vinculando os trabalhadores, por meio de contratos precários, a exercer atividades em espaços físicos inadequados; ou em virtude da dissociação das bases teóricas do modelo em relação à realidade socioeconômica e psicossanitária da cidade; ou, ainda, em razão da permanência concreta dos dispositivos asilares que tanto se intencionava superar.

Dessa forma, Guimarães (2012) alerta para a necessidade de incluir nas avaliações das políticas, planos, programas, redes, sistemas e serviços de saúde e projetos terapêuticos a dialética das relaçōes entre conjuntura social e natureza dos dispositivos, gestão e atenção, bem como entre eficiência e efetividade. $\mathrm{O}$ autor aponta os impasses da Reforma Psiquiátrica e indica novos caminhos para a política de saúde mental em Fortaleza, Ceará. Destaca, ainda, a ocorrência de debates entre técnicos e a formulação equivocada de princípios, diretrizes e prioridades, com lista de dispositivos e ações, mas que não envolveram a sociedade e não ensejaram a edição de uma lei municipal. 
Com base nessas constatações, formularam-se algumas questões norteadoras deste estudo, dentre elas: quais são as características do modelo proposto, que completa uma década de esforços de implantação, na percepção de usuários, trabalhadores e gestores? O que é percebido pelos usuários, trabalhadores e gestores em referência aos mal-estares produzidos pela prática atual e seus determinantes no contexto de implementação do modelo de atenção psicossocial territorial?

Para operacionalizar o estudo, elegeu-se como objetivo compreender a implantação do modelo de atenção psicossocial territorial, considerando seus avanços e desafios na produção do cuidado, no contexto da Reforma Psiquiátrica em Fortaleza, Ceará.

\section{Tratamento metodológico}

Trata-se de pesquisa qualitativa, orientada pelo método dialético, cujo desenho é o estudo de caso. $\mathrm{O}$ método dialético parte do objeto, em sua contextualização histórica, tendo como meta sua reconstituição teórica. Permite uma compreensão de uma realidade concreta, mediante a identificação dos conflitos e das contradiçốes estabelecidas na relação entre as partes que a compõem. Seu procedimento é dinâmico, portanto, com múltiplas possibilidades de (re) constituição do conhecimento, onde sujeito e objeto, se inter-relacionam e se fazem um ao outro (SAMPAIO, 1998). Assim, a aproximação com o método dialético justificou-se por permitir a análise do(s) modelo(s) de saúde mental operado(s) em uma capital do Nordeste brasileiro, abrangendo suas inter-relações.

O estudo de caso é uma investigação empírica de um fenômeno contemporâneo, que permite evidenciar ligações causais entre intervenções e seus efeitos, o contexto de ocorrência de uma ação ou intervenção, o rumo de um processo em curso e as maneiras de interpretá-lo, bem como o sentido e a relevância de situações-chave nos resultados de uma intervenção (MINAYO, 2011).

Assim, selecionou-se como caso a Secretaria Regional III (SR-III), do município de Fortaleza, por se considerar que nela foi inaugurado o primeiro CAPS. Atualmente, em seu território, existem um CAPS geral, um CAPS para álcool e outras drogas (CAPSad) e um CAPS infantil (CAPSi), denotando as características fundamentais de pioneirismo, portanto, tempo maior de experiência, bem como de complexidade da rede instalada de atenção à saúde mental. Ressalta-se que o município é subdividido, para fins administrativos, em sete SR. 
Foram técnicas de coleta de dados a entrevista e o grupo focal. Entrevistaramse cinco gestores: do CAPS geral, do CAPSad, do CAPSi, o Articulador Regional de Saúde Mental e o Coordenador Municipal de Saúde Mental. Realizaram-se grupos focais com os trabalhadores que aderiram: um em cada CAPS, envolvendo de nove a 13 participantes, totalizando três grupos focais, com 33 participantes. Por fim, foram efetivados os grupos focais com os usuários que aderiram: dois em um serviço e um em cada qual dos outros dois serviços de saúde mental, cada grupo envolvendo seis usuários, totalizando quatro grupos focais com 24 usuários.

Os dados foram submetidos à Análise do Discurso Coletivo, de acordo com os delineamentos expressos por Lefèvre e Lefèvre (2010), que consiste na análise e categorização de respostas, atribuindo-lhes sentido, e, em seguida, agrupandoas em categorias homogêneas.

A pesquisa foi aprovada pelo Comitê de Ética em Pesquisa da Universidade Estadual do Ceará.

\section{Resultados e discussão}

O material procedente do discurso dos gestores, trabalhadores e usuários permitiu a estruturação das categorias empíricas delineadas.

\section{A implantação do modelo de atenção psicossocial}

O discurso do sujeito coletivo evidencia a intencionalidade de implantação do modelo psicossocial, que tem avançado, sobretudo, em relação à inauguração de serviços constitutivos da RAPS, como resultado da Reforma Psiquiátrica.

\footnotetext{
A gente avançou em muitos processos, em número de serviços, CAPS, NASF [Núcleo de Apoio a Saúde da Família], RT [Residência Terapêutica], apontando para a construção real de uma rede de saúde mental mínima na cidade, mas, de dois anos para cá, houve a desconstrução disso tudo. Estamos retrocedendo. O psicossocial venceu no discurso, mas ficou lá. É como se bastasse o discurso. A ideia é boa, mas ainda não ocorreu a mudança. (DSC)
}

Evidencia-se, no entanto, um descompasso entre a proposição do modelo psicossocial e a sua efetiva materialização, constituindo desafio à sua consolidação. Tal situação parece ter múltiplos determinantes, entre eles: o modelo de gestão, o financiamento, a qualificação das equipes, a precarização do trabalho, o que reforça a necessidade de subsistência do hospital psiquiátrico como recurso terapêutico. 
Não é o ideário da Reforma Psiquiátrica que está falindo, é a gestão, é o financia-

mento, é a preparação das equipes, é a precarização do trabalho que não têm permitido que os CAPS funcionem dentro de uma perspectiva aberta, coletiva, integral, de respeito à cidadania das pessoas, porque a gestão municipal reforça essa coisa da internação e não investe nas equipes dos CAPS. (DSC)

Os determinantes evidenciados também foram encontrados por Guimarães (2012), que os considera expressão da desresponsabilização da gestão municipal em relação à gestão do trabalho e à gestão da atenção psicossocial. Considera-se, porquanto, que o êxito na implementação de um modelo de atenção depende das condições para sua operacionalização, ofertadas pelo modelo de gestão, o que põe em relevo a indissociabilidade gestão e atenção (ABREU-DE-JESUS, 2006).

Não obstante, percebe-se que são identificados traços marcantes do modelo psicossocial, expressos no entendimento de que o serviço deve ser aberto, desenvolvendo cuidado individual e coletivo, no qual haja apropriação deste pelo usuário. Remete, ainda, à importância de o cuidado ser efetivado em seu contexto social, ajudando-o a lidar com as adversidades do meio em que vive e não de forma segregada em uma instituição.

A gente escuta deles próprios que o CAPS é como se fosse a segunda casa deles. [Por outro lado] é sempre dito para os profissionais: o CAPS é deles, não nosso, e o paciente tem que se sentir bem aqui. Eu acredito que, se a reforma fosse efetiva, o tratamento deveria ser ambulatorial no CAPS, para que a pessoa não saísse do contexto, da vida familiar, do meio em que vive (DSC).

Apesar do entendimento de que os CAPS materializam dimensões do modelo psicossocial, ressalta-se que, ao considerá-los como segunda casa, corre-se o risco de desencadear processos de alienação, assistencialismo e novos modos de institucionalização, indo na contramão da proposta de construção de autonomia e cidadania. Nesse sentido, o discurso revela, ainda, que esses serviços têm-se distanciado de uma diretriz basilar que é a articulação territorial.

Hoje, ainda, o serviço se presta a fazer um papel ambulatorial centralizado no CAPS [...]. Nós temos o terapeuta ocupacional, o assistente social, mas tudo ainda está voltado para atuação dentro do serviço, pois o território ainda não aparece (DSC).

Evidencia-se que, sobretudo na perspectiva dos trabalhadores, a compreensão é, fundamentalmente, do CAPS como um serviço ambulatorial, desperdiçado como local de criação e de passagem, mas com uma atuação "capscentrada", que o configura como novo local de cronificação. 
Diante da dificuldade de articulação no território, como espaço de produção de saúde, gera-se a percepção de que o CAPS tem perdido sua potência transformadora das práticas de saúde mental.

Quantos anos levamos desde a construção da Reforma Psiquiátrica para que a ideia se disseminasse no meio da sociedade e fosse absorvida! Os serviços CAPS foram surgindo e as pessoas foram se apropriando, foi sendo estabelecida uma legitimidade. Hoje, a gente observa que o serviço não dá mais conta, perdeu potência criativa, retrocedeu. (DSC)

Reconhece-se que a inserção territorial e a legitimidade da população constituem estratégia para abordagem de aspectos socioculturais, como dimensão da Reforma Psiquiátrica, voltados à construção de outro lugar social do sujeito em sofrimento psíquico e de novos modos de lidar com a loucura, superando o estigma e o preconceito, conforme defendido por Amarante (2007). Entretanto, o que se percebe na prática é a constituição de outras formas de cronificação, de institucionalização e de segregação (PANDE; AMARANTE, 2011).

Nessa lógica de atuação, os CAPS redirecionam suas práticas para uma abordagem reducionista do usuário, centrada na clínica individual, tratando-o como objeto. Identificam-se, no entanto, contradições entre a prática e o discurso, pois também reconhecem que deveriam considerar o usuário como sujeito em sua experiência de vida.

O que se observava era que o usuário era tido como objeto de estudo. Então, vinham os médicos e residentes que precisavam passar pela saúde mental, portanto pelo CAPS. O usuário chegava ao serviço e ninguém se aproximava. Era como um spectrum, um fantasma. Acho que se fosse um rato que tivesse passando o pessoal notava mais. A gente não devia trabalhar com diagnóstico, a gente trabalha com vidas, com existências, com relaçôes. (DSC)

Reconhece-se, ainda, que, apesar da perspectiva medicamentosa e manicomial, referenciada principalmente pelos trabalhadores, boa parte dos usuários visualizam práticas mais condizentes com o modelo da atenção psicossocial territorial, especialmente no que se refere ao medicamento e ao atendimento da equipe, sobretudo no caso dos CAPSi e CAPSad.

O remédio só vai fazer efeito pra eles dormirem e pronto. O restante, que é a parte deles conversarem, acontece com os psicólogos. Mas nem todos precisam do medicamento. No caso da criança, acredito que o remédio não tenha tido muito efeito. $\mathrm{O}$ modo como recebem e passam as coisas para as crianças é que é importante [...] $\mathrm{O}$ carinho ajuda mais que o remédio. O remédio é muito bom pra a doença, mas pra vida 
é a conversa. No caso do usuário de droga, lá fora é tachado de bandido, sem vergonha,

vagabundo, e aqui a gente aprende que é doença e como tratar, é bem acolhido. (DSC)

Diante da dissonância entre os princípios e a implementação do modelo psicossocial, emerge uma perspectiva de culpabilização da gestão municipal, alçada como "bode expiatório", de quem trabalhadores esperam condições ideais para o trabalho.

Parece haver uma estratégia de produzir a ideia de falência desse novo modelo, para fortalecer o modelo asilar e legitimar seu retorno. A política de saúde mental é uma política de governo e não de Estado. Ela é tratada com descaso real e absoluto com a rede. A gente tem que entender que não se pode atribuir a responsabilidade ao serviço. A questão é muito maior, é estrutural. Se a equipe não tivesse compromisso com o usuário e com a política de saúde mental, como de fato teve e tem, a gente deixava logo transformar isso aqui num hospital psiquiátrico. O problema é que os gestores nem aparecem. Quando aparecem é para ameaçar corte e deixar os profissionais acu$\operatorname{ados}(\mathrm{DSC})$.

Em diversos estudos desenvolvidos em Fortaleza, em distintos períodos, têm-se evidenciado resultados semelhantes em que, sobretudo, os trabalhadores apontam dissonâncias com a Reforma Psiquiátrica, precarização do trabalho e falta de condições de trabalho, tensionamentos políticos e técnicos entre gestores e trabalhadores. Expressam sinais de desresponsabilização da gestão municipal com efetiva implementação da RAPS e do modelo de atenção psicossocial territorial, configurando um problema crônico no município sob análise (GUIMARÃES, 2012; GUIMARÃES; JORGE; ASSIS, 2011; SAMPAIO; GUIMARÃES; ABREU, 2010; JORGE, et al, 2007).

Por outro lado, evidencia-se no plano discursivo, sobretudo por parte dos trabalhadores, uma intencionalidade de se efetivar práticas condizentes com o modelo de atenção proposto para os CAPS.

Eu tenho muito desejo: de que esse modelo de atenção psicossocial possa ser implantado de forma decente e coerente. É preciso tensionar para que essas diretrizes clínicas sejam amplas, não ligadas meramente a questôes de sinais, sintomas, diagnósticos. Eu participei de dois projetos de inserção social: o bloco de carnaval "Doido é Tu" e o projeto de teatro "Escuta em Cena". É a questão da valorização da autoestima e da criatividade, pela música, pela dança, e pela representação. Pararam... não tem mais... não sei o que fazer. Eu acho realmente muito boa a proposta do CAPS, mas a grande questão é que fica atrelada ao modelo hospitalocêntrico. (DSC)

Apesar da tensão e convivência dos dois modelos, reconhecem a proposta do CAPS como alternativa, embora não consigam desenvolvê-la em 
1222 plenitude. Não obstante, visualizam ações possíveis de serem realizadas ou que já foram operadas em outros momentos, porém foram capturadas pela lógica manicomial. Há evidências de um discurso no campo da abstração, desprovido de posicionamento político prático, porém, com a sinalização de uma aparente possibilidade de constituição de compromissos, que poderá ser processada no cotidiano da organização, sendo perpassada pelos processos intersubjetivos operados na prática concreta dos serviços. Percebe-se, então, o papel do imaginário na organização. Segundo Castoriadis (1982), a práxis dos humanos, bem como a de suas instituiçôes, resulta da tensão entre componentes concretos e imaginários, caracterizando a instituição como uma rede simbólica, socialmente sancionada.

O imaginário constitui uma maneira de representar aquilo que as pessoas são, o que querem vir a ser, o que querem fazer e em que tipo de sociedade e de organização se deseja intervir. Assim, é permeado por desejos, imagens e representações psíquicas compartilhadas pelos membros do grupo/organização, sendo transpassado por processos inconscientes, intimamente articulados ao sistema simbólico, funcionando como balizadores da atuação dos indivíduos, produzindo sentidos para suas ações. Há, portanto, um investimento psíquico dos indivíduos em determinado imaginário, o que fundamenta a constituição do grupo/organização, possibilitando a efetiva realização de projetos (VASCONCELLOS; AZEVEDO, 2010). Assim, o investimento psíquico dos trabalhadores, apoiado também na postura política e ideológica adotada por esses sujeitos, colaborando para a constituição de compromissos com a organização, apesar do contexto adverso, está na possibilidade de substituição dos modelos asilar/psiquiátrico clássico pela atenção psicossocial territorial, como estratégia para materializar a Reforma Psiquiátrica (GUIMARÃES, 2012).

Apesar dessa conjuntura, o discurso dos usuários expressa reconhecimento em relação à qualidade e resolubilidade em ambos os CAPS.

O CAPS infantil tem ambiente estranho. Mas o atendimento é excelente. Parece que no CAPS eles juntaram os bons profissionais. Eles dão atenção mesmo e realmente suprem as necessidades; bem diferente [de antes] (DSC).

Nesses termos, as dimensões do cuidado nos CAPS ganham contornos centrais na relação profissional-usuário, que se desenvolve com base no acolhimento e construção de vínculos. 


\section{A (re)produção dos modelos asilar e psiquiátrico clássico}

No discurso a seguir, é possível identificar a dependência apontada, tanto do profissional médico quanto dos medicamentos. Muitos trabalhadores ficam sem saber o que fazer sem a condução biomédica.

Sem a figura do médico, a equipe desmorona, os profissionais ficam sem condição de trabalho local, e aí a gente fica encaminhando para o Hospital de Saúde Mental de Messejana. A gente é como se fosse um apêndice do hospital. Além disso, precisa ter o suporte da medicação; quando não tem, fica muito difícil trabalhar. A maioria não tem perfil para [ficar] aqui. Se chegar uma criança com comportamento muito alterado, a gente acolhe por falta de opção; vai só ficando. O CAPS só está servindo como porta de entrada para internação. (DSC)

A centralidade no médico reduz as possiblidades de intervenção na crise, em que as equipes não visualizam outras estratégias de produção do cuidado. Nesses termos, perdem-se de vista as possíveis vantagens - ideológicas, técnicas e organizacionais - do trabalho em equipe na lógica interdisciplinar, necessárias para se alcançar os objetivos específicos da clínica psicossocial (SAMPAIO et al., 2011).

Constata-se que os CAPS se constituíram porta de entrada para a internação psiquiátrica, entendida como refúgio, subsistência, respaldada pela administração pública como recurso terapêutico quase que exclusivo, reforçando a subsistência do modelo psiquiátrico clássico. O hospital psiquiátrico é visto como lugar de salvação ou resolução. Pressionados pela demanda desordenada e excessiva, os trabalhadores passam a estabelecer perfis de usuário para atendimento, daí a segregação interna nos serviços, adicional à segregação social, no entanto, visto dessa forma, como um retrocesso da política, um círculo vicioso.

O preconceito diminuiu com a Reforma Psiquiátrica. Sem o CAPS, a coisa era assim: é louco? Tem que internar. Quando cheguei aqui, [a criatividade] estava a todo vapor e a gente conseguia fazer a atenção psicossocial funcionar. Raramente se falava em hospital psiquiátrico, éramos resolutivos. Porém, hoje eu acho que essa procura está mais ligada à pressão por internação. Acho isso um retrocesso da política. Muitos querem a internação como refúgio. Temos um círculo vicioso. Tem paciente da gente que há muito tempo não internava e agora, de um ano para cá, já internou três ou quatro vezes. É triste viver isso. A gente trabalha com todos esses elementos de comunidade, inserção social, trabalho, família, escola, entendeu? Mas, aos pedaços, como se fosse uma pizza, tendo o CAPS no meio, como o antigo hospital. Tem muitas pessoas, muitos trabalhadores e gestores que funcionam, no nível do pensamento e no das práticas, dentro do modelo antigo. (DSC)

Emergem como determinantes da internação não somente as dificuldades da equipe, que atua com pouca articulação e com predominância da lógica 
ambulatorial segmentada, mas também a pressão dos usuários e familiares, em todos os tipos de CAPS, considerando as especificidades do serviço. Nesse sentido, reforça-se a ideia de que a sociedade tem desejo de manicômio, o que constitui um desafio aos processos de desinstitucionalização (ALVERGA; DIMENSTEIN, 2006).

O retrocesso relatado sucede uma época em que a atenção psicossocial acontecia na base da criatividade e resolutividade da equipe, sendo o hospital psiquiátrico pouco utilizado na rotina. Convém assinalar que não se desconhece a internação como possível recurso terapêutico, mas devendo ser utilizada quando todos os recursos territoriais falharem. Adverte-se, porém, que, no contexto da atenção psicossocial territorial, a internação psiquiátrica deverá ocorrer em hospital geral, como integrante da rede, e não em hospital psiquiátrico (GUIMARÃES, 2012; QUINDERÉ; JORGE; FRANCO, 2014). Não obstante, o município de Fortaleza não conta com leitos suficientes para internação de sujeitos com transtornos mentais em hospital geral. Os leitos disponíveis se destinam principalmente à desintoxicação de usuários de álcool e outras drogas. A equipe partilha com os usuários - em relação ao portador de transtorno mental e ao dependente químico - vários preconceitos associados à vadiagem, aos riscos de violência e à dificuldade em aceitar o tratamento. $\mathrm{O}$ que aparece nos resultados é a permanência de visões contemporâneas ao século XVIII. O profissional não se questiona e não se vê como parte do processo, fazendo com que se mantenha em posição assistencialista. Acrescenta-se, ainda, o papel da família, nem sempre presente, como apoiadora e compreensiva, mas, também, como necessitando de cuidados.

Quando entrei aqui no CAPS, eu pensei que os pacientes tivessem interesse em ficar bom [...]. Com a convivência, eu notei que eles só vêm [se tratar] se tiver vale-transporte. [Mas] eles levam os vales para o traficante. Não têm interesse em ficar bom, querem é vender a comida, o lanche, o almoço, o vale-transporte. Se eles tivessem interesse, realmente, em se tratar, eles achariam o apoio da gente. O que falta é algo que, eu acho, tem muito a ver com a família, porque se não há o apoio e a compreensão da família, eles, sozinhos, não conseguem. Aquela pobrezinha [uma terapeuta ocupacional] ali só falta apanhar deles. Eu observo muito, eles são muito perigosos, são muito rebeldes. (DSC)

O preconceito e a visão estigmatizada por parte de alguns trabalhadores dificultam o cuidado àqueles com histórico de uso abusivo de substâncias psicoativas, favorecendo com que se perpetue a forma negligenciada e ineficaz 
da assistência, reforçando, ainda, a marginalização perante a sociedade. A desarticulação entre os serviços também se torna evidente.

O que dificulta muito é a forma como os usuários do ad são tratados, não é só o vale-transporte, não é só a falta de alimentação, não é só isso. Os meninos do ad reclamam muito da forma como são tratados pelos profissionais. Vez por outra, passando por dentro do CAPSad, eu escutava que ali só havia marginal. Quando a gente traz usuário do ad pra cá, eu vejo o segurança tratar diferente e o pessoal da merenda reclamar. É um serviço só e temos que acolher todos (DSC).

Desse modo se reproduz, efetivamente, o modelo psiquiátrico/manicomial, no qual o usuário é um expectador do próprio tratamento, pois não tem voz ativa e é visto de forma fragmentada pelo profissional médico, detentor do conhecimento e do poder de saber melhor do que o próprio usuário sobre sua condição de saúde ou doença. Essa lógica se repete nas demais profissões que atuam na saúde (QUINDERÉ et al., 2010).

\section{A (des)articulação da Rede de Atenção Psicossocial}

Entende-se que a produção do cuidado em saúde mental, na perspectiva do modelo psicossocial territorial, deve ocorrer em ações e serviços articulados em níveis de complexidade crescente, configurando uma rede de atenção à saúde, como estratégia de construção da integralidade do cuidado (PAES et al., 2013).

A RAPS de Fortaleza é composta de equipamentos diversos, mas sua articulação é insuficiente. Nesse sentindo, o discurso revela fragilidade na execução de trabalho em rede e uma compreensão limitada de território como espaço de produção de saúde. Os profissionais, geralmente, parecem estar engessados em seus espaços físicos e em alguns ideais apartados de qualquer prática psicossocial no território.

Na verdade, a gente tá só. Há uma grande falta de apoio, de suporte da rede. Eu sinto essa falta do trabalho em rede. Você não tem pra onde encaminhar, às vezes até tem, mas há limite de vagas. Aí você e o paciente ficam perdidos. Você até pode tratar da doença aqui, mas e o cuidado com a vida dele? Não existem as parcerias; a gente tem dificuldade desde a gestão municipal anterior. Os autistas ficam adultos e os CAPS gerais não querem receber o autista adulto (DSC).

Evidencia-se a ampliação quantitativa de serviços, particularmente CAPS, no entanto, desacompanhada de mecanismos de articulação e regulação. Desse modo, não foram construídos fluxos assistenciais que efetivem a conectividade 
entre os distintos serviços da rede, o que dificulta o encaminhamento dos usuários que necessitam ser atendidos em outros serviços de saúde, contribuindo, assim, para a descontinuidade do cuidado em saúde mental, gerando demanda reprimida e estrangulamento da capacidade de atendimento.

A desarticulação da RAPS parece um problema estrutural e crônico, em que se aponta a responsabilidade da gestão municipal. Dela se requisitam intervençôes com vistas a promover a articulação e envolvimento dos diferentes serviços e setores para efetivar uma RAPS resolutiva e com qualidade da atenção à saúde (GUIMARÃES, 2012; PAES et al., 2013).

Nesse cenário, alguns gestores locais e trabalhadores, na perspectiva de atender as necessidades dos usuários, buscam estabelecer mecanismos de articulação com outros serviços de saúde. Entretanto, o máximo que se tem conseguido, com dificuldade, e ainda de forma contingencial, é a articulação com a Atenção Primária e com o Serviço de Atendimento Móvel de Urgência (SAMU).

A gente está tentando fortalecer uma articulação com a atenção primária. Quando cheguei, eu consegui mostrar à atenção básica que eu precisava deles e hoje esses nossos usuários já estão sendo atendidos. Mas nem o pessoal da atenção básica, nem os usuários, querem isso; fazem por obrigação. Quando a gente liga para o SAMU e eles veem que é do CAPS ad, acho que já reagem com preconceito. Eles dizem que tem casos mais urgentes para atender. Tem pessoa que apresenta convulsão por causa da bebida e eles não atendem. A gente fica aqui, de tarde, com um paciente precisando de ambulância e espera quatro a cinco horas. Às vezes, liga pro SAMU e ele não vem (DSC).

O discurso sinaliza que, inicialmente, a articulação estabelecida entre CAPS e atenção básica foi operada com base no apoio matricial, no entanto, há descontinuidade.

O matriciamento das equipes de Saúde da Família era feito há tempos. Hoje não acontece. Não tem mais o trabalho com a atenção primária que a equipe desenvolvia aqui (DSC).

Destaca-se que o apoio matricial, executado pelo CAPS, tem na Estratégia Saúde da Família (ESF) a equipe de referência, ao mesmo tempo, arranjos organizacionais e uma metodologia para a gestão do trabalho em saúde, com objetivo de ampliar as possibilidades de se realizar clínica ampliada e integração dialógica entre distintas especialidades e profissões (CAMPOS; DOMITTI, 2007).

De acordo com Morais e Tanaka (2012), a operacionalidade do apoio matricial em Fortaleza foi marcada por limitaçôes, entre as quais se destacam 
a indisponibilidade dos profissionais, dificuldade em manter o seguimento dos casos de saúde mental - decorrente do despreparo para lidar com a dimensão subjetiva - e postura passiva dos profissionais mediante a lógica de gestão ainda verticalizada, sem comando efetivo em relação ao matriciamento.

Ademais, a dificuldade de lidar com a dimensão subjetiva no território, por parte da atenção básica, tem reforçado a ideia de que o usuário com sofrimento psíquico é exclusividade do CAPS, não sendo passível de acometimentos clínicos que requerem intervenção médica em outras especialidades. Reproduz-se, assim, a lógica de fragmentação do cuidado, a dicotomia mente e corpo.

É como se o usuário com transtorno mental não tivesse questões clínicas de outra ordem, como se não fosse de responsabilidade da atenção primária, só do CAPS. Tem os encaminhamentos inadequados, tem o medo de trabalhar com pessoas com algum transtorno mental (DSC).

Destaca-se, ainda, que a atenção básica é utilizada não como corresponsável na produção do cuidado, como substituta particularmente do CAPS geral, em decorrência da falta de médicos.

A gente apenas encaminha, sem a perspectiva conceitual do matriciamento. Faltar médico no serviço foi oportunidade para fazer o paciente ir para a atenção básica, que o CAPS é atenção secundária... o paciente é nosso e da atenção básica. Eles recebem receita lá, mas têm que vir para cá receber os remédios. Que articulação é essa que aumenta os caminhos do usuário? (DSC)

Quando há a articulação em rede, a concepção do trabalho terapêutico para a autonomia da pessoa se amplia, pela participação do usuário, o que representa um grande diferencial, uma vez que, apropriando-se do projeto terapêutico, ele experimenta a apropriação da sua vida (PINHO; HERNÁNDEZ; KANTORSKI, 2010).

\section{Considerações finais}

Os achados do estudo evidenciam confluências e dissonâncias com os princípios do modelo de atenção psicossocial territorial no processo de implementação da Reforma Psiquiátrica no município de Fortaleza. Nesses termos, identifica-se, no plano discursivo, intencionalidade de implantação do modelo, bem como suas características fundamentais com marcante descompasso na sua materialização.

Assim, ocorrem avanços na expansão do número de serviços constitutivos da RAPS, mas com persistentes desafios na qualificação das práticas operadas 
nos CAPS, que vêm atuando de maneira desarticulada com os demais serviços de saúde, com reduzida inserção no território como espaço de produção de saúde. Como consequência, a produção do cuidado direciona o foco para a clínica individual, com ênfase na prescrição medicamentosa, em que o usuário é reduzido à condição de objeto, desconsiderando a subjetividade e singularidade de cada sujeito em sua experiência de vida. Nesse panorama, os CAPS vêm se configurando como serviços ambulatoriais, com atuação centrada no profissional médico, sem desenvolvimento de uma clínica orientada pela atenção psicossocial, perdendo a sua potência de transformação das práticas de saúde mental, considerando a mediação de projetos de vida e reinvenção de saúde.

Ademais, a inserção dos CAPS no território não tem se configurado como estratégia efetiva para a articulação com os demais serviços de saúde, na perspectiva de constituição de redes de atenção, o que se constata mediante o não estabelecimento de fluxos assistenciais que assegurem os encaminhamentos dos usuários. Os vínculos institucionais parecem frágeis. Assim, não conseguem efetiva parceria com os diversos equipamentos, particularmente SAMU e atenção básica.

No que se refere à atenção básica, houve processos de articulação por meio do apoio matricial, que não se consolidou. Na carência de profissionais médicos nos CAPS, a atenção ao usuário fica prejudicada, em virtude de os demais profissionais não desenvolverem outras possibilidades de cuidado. Assim, tensionam a atenção básica para atender essa demanda; diante da dificuldade de lidar com a dimensão subjetiva, restringe-se o atendimento à dispensação de prescrição médica, sem vislumbrar possibilidades de intervenções mais amplas no território. Na tensa relação CAPS e atenção básica, o usuário é tratado de forma fragmentada, reproduzindo a dicotomia mente e corpo.

Essa conjuntura tem múltiplas determinações, que se relacionam com a qualificação das equipes, as condições de trabalho, o financiamento, o modelo de gestão e os conflitos e contradições entre os discursos e as práticas dos distintos sujeitos envolvidos na produção de saúde. Tudo isso acaba por reforçar a subsistência do modelo de atenção asilar/psiquiátrico clássico, expressa, principalmente, na reificação do hospital psiquiátrico como recurso terapêutico - quando o CAPS é considerado como porta de entrada para a internação nestes nosocômios. 
Convém assinalar que mesmo reconhecendo o CAPS como modelo potente para transformação da atenção à saúde mental, os trabalhadores ainda reproduzem práticas que expressam assistencialismo, induzem a segregação e o estigma, o que se contrapõe às propostas de construção de autonomia, vínculos solidários e resgate da cidadania do sujeito em sofrimento psíquico. Nesses termos, o CAPS corre o risco de produzir novas formas de cronificação e de institucionalização.

Desse modo, a reprodução do modelo asilar/psiquiátrico clássico precisa ser superada, com vistas à consolidação do modelo psicossocial territorial. Isso requer investimento de todos os sujeitos, sobretudo da gestão municipal, no sentido de oferecer condições para que se desenvolvam processos de qualificação das equipes, articulação entre os serviços integrantes da RAPS, de modo efetivo, com fluxos assistenciais que permitam atender as necessidades de saúde dos usuários e condições de trabalho satisfatórias. Destaca-se, ainda, a necessidade de se implantar supervisão clinico-institucional, como dispositivo para qualificar a clínica e os processos de trabalho na atenção psicossocial territorial. ${ }^{1}$

\section{Referências}

ABREU-DE-JESUS, W.L. SUS-Alagoinhas: um modelo de gestão/atenção para a transformação de sujeitos e coletivos. Divulgação em Saúde para o debate, n. 36, p. 61-75, 2006. ALVERGA, A.R.; DIMENSTEIN, M. A Reforma Psiquiátrica e os desafios na desinstitucionalização da loucura. Interface - Comunicação, Saúde, Educação, v. 10, n. 20, p. 299-316, 2006.

AMARANTE, P. Saúde mental e atenção psicossocial. Rio de Janeiro: Editora Fiocruz, 2007. BRASIL. Ministério da Saúde. Legislação em saúde mental: 1990-2004. 5. ed. Brasília: Ministério da Saúde, 2004.

CAMPOS, R.T.O. et al. Avaliação da rede de centros de atenção psicossocial: entre a saúde coletiva e a saúde mental. Rev. Saúde Pública, v. 43, n. supl. 1, p. 16-22, 2009.

CAMPOS, G. W. S.; DOMITTI, M. S. Apoio matricial e equipe de referência: uma metodologia para gestão do trabalho interdisciplinar em saúde. Cad. Saúde Pública. Rio de Janeiro, v. 23, n. 2, p. 399-407, 2007.

CASTORIADIS, C. A instituição imaginária da sociedade. 6. ed. Rio de Janeiro: Paz e Terra, 1982.

GRUPO O POVO. Anuário do Ceará: 2014. Fortaleza: Grupo de Comunicação O POVO, 2014. 

em saúde mental: um estudo em Centros de Atenção Psicossocial. Ciênc. saúde coletiva. Rio de Janeiro, v. 16, n. 4, p. 2145-2154, 2011.

GUIMARÃES, J. M. X. Inovação e gestão em serviços de saúde mental: incorporação de tecnologias e reinvenção no cotidiano dos centros de atenção psicossocial. 2012. 286p. Tese (Doutorado em Saúde Coletiva) - Universidade Estadual do Ceará - Fortaleza. 2012.

JORGE, M. S. B. et al. Gestão de recursos humanos nos centros de atenção psicossocial no contexto da Política de Desprecarização do Trabalho no Sistema Único de Saúde. Texto contexto - enferm., v. 16, n. 3, p. 417-425, 2007.

LEFEVRE, F.; LEFEVRE, A. M. C. O Discurso do Sujeito Coletivo como superação dos impasses no processamento de respostas a questões abertas. In: $O$ discurso do sujeito coletivo. Curso teórico prático de introdução ao discurso do sujeito coletivo e ao software qualiquantisoft. Instituto de Pesquisa do Sujeito Coletivo. São Paulo, 2010.

MORAIS, A.P.P.; TANAKA, O.Y. Apoio matricial em saúde mental: alcances e limites na atenção básica. Saúde soc., v. 21, n. 1, p. 161-170, 2012.

PAES, L.G. et al. Rede de atenção em saúde mental na perspectiva dos coordenadores de serviços de saúde. Trab. educ. saúde, v. 11, n. 2, p. 395-409, 2013.

PANDE, M. N. R.; AMARANTE, P.D.C. Desafios para os Centros de Atenção Psicossocial como serviços substitutivos: a nova cronicidade em questão. Ciênc. saúde coletiva. Rio de Janeiro, v. 16, n. 4, p. 2067-2076, 2011.

PINHO, L. B.; HERNÁNDEZ, A. M. B.; KANTORSKI, L. P. Serviços substitutivos de saúde mental e inclusão no território: contradições e potencialidades. Ciênc. Cuid. Saúde, v. 9, n. 1, p. 28-35, 2010.

QUINDERÉ, P. H. D. et al. A convivência entre os modelos asilar e psicossocial: saúde mental, Fortaleza-CE. Saúde em debate, v. 34, n. 84, p. 137-47, 2010.

QUINDERÉ, P. H. D.; JORGE, M. S. B.; FRANCO, T. B. Rede de Atenção Psicossocial: qual o lugar da saúde mental? Physis: Revista de Saúde Coletiva, v. 24, n. 1, p. 253-271, 2014. SAMPAIO J. J. C.; GUIMARÃES, J. M. X.; ABREU, L. M. Supervisão clínico-institucional e a organização da atenção psicossocial no Ceará. São Paulo: Editora Hucitec; 2010.

SAMPAIO, J. J. C.; SANTOS, A. W. G. A experiência do Centro de Atenção Psicossocial e o Movimento Brasileiro de Reforma Psiquiátrica. In: PITTA, A. (Org.) Reabilitação Psicossocial no Brasil. 2. ed. São Paulo: HUCITEC, 2001.

SAMPAIO, J. J. C. et al. O trabalho em serviços de saúde mental no contexto da Reforma Psiquiátrica: um desafio técnico, político e ético. Ciênc. Saúde Coletiva. Rio de Janeiro, v. 16, n. 12, p. 4685-4694, 2011. 
SAMPAIO, J. J. C. A humanização da saúde. In: CARNEIRO, C. et al. (org.). Acolher cidadão: estratégia de aperfeiçoamento do SUS em Quixadá, Ceará. Fortaleza: EdUECE, 2006. p. 21-26.

SAMPAIO, J. J. C. Epidemiologia da imprecisão: processo saúde/doença mental como objeto da epidemiologia. Rio de Janeiro: Fiocruz, 1998. 133p.

SILVA, M. T.; LANCMAN, S.; ALONSO, C. M. C. Consequências da intangibilidade na gestão dos novos serviços de saúde mental. Rev. Saúde Pública, v. 43, v. supl. 1, p. 36-42, 2009.

VASCONCELlOS, V. C.; AZEVEDO, C. S. Sentidos do trabalho e imaginário organizacional em um Centro de Atenção Psicossocial - CAPS. Interface - comunicação, saúde, educação, v. 4. n. 34, p. 563-576, 2010.

\section{Nota}

${ }^{1}$ J.M.S. Nunes participou da concepção do projeto; da coleta, análise e interpretação dos dados; redação do artigo e revisão crítica do conteúdo intelectual, bem como da aprovação da versão final a ser publicada. J.M.X. Guimarães participou da análise e interpretação dos dados; redação e revisão crítica do conteúdo intelectual; aprovação da versão final a ser publicada; J.J.C. Sampaio participou da concepção do projeto; redação e revisão crítica do conteúdo intelectual, bem como aprovou a versão final a ser publicada. Não há conflito de interesses. 
The production of mental health care:

achievements and challenges to the

implementation of the territorial psychosocial care model

This research aims to understand the reasons for implementation of the territorial psychosocial care model, its advances and challenges in the production of care, in the current psychiatric reform movement that took place in Fortaleza, Ceara State, Brazil. The research is a qualitative research, a case study, and historically contextualized approach to the dialectical method, technically through interviews and focus group with results submitted to the analysis of collective discourse. The results and discussion are expressed in categories that emerged in the discourse of workers, managers and users, related to the classic psychiatric and the territorial psychosocial care models. The final remarks indicates that both, the hospital model and the territorial psychosocial care model, are living together, and there was not overcome the first by the second. Although the prospect of an inclusive and integrated action policy, the transit to the practice is discontinuous and fragmented. So the model of the territorial psychosocial care is presented currently outside the realm of services, odd / alienated, without many prospects for establishing and implementing in the city of Fortaleza.

> Keywords: mental health; mental health services; health care. 